\title{
Performance Improvement of Wave-Like PEMFC Stack with Compound Membrane Electrode Assembly
}

\author{
P. Y. Yi ${ }^{1}$, L. F. Peng ${ }^{1}$, X. M. Lai ${ }^{2 *}$, Z. Q. Lin ${ }^{2}$, J. $\mathrm{Ni}^{3}$ \\ 1 State Key Laboratory of Mechanical System and Vibration, Shanghai Jiao Tong University, Shanghai 200240, P. R. China \\ 2 Shanghai Key Laboratory of Digital Autobody Engineering, Shanghai Jiao Tong University, Shanghai 200240, P. R. China \\ 3 Department of Mechanical Engineering, University of Michigan, Ann Arbor, MI 48109-2125, USA
}

Received June 13, 2012; accepted August 07, 2012

\begin{abstract}
The novel architecture of wave-like proton exchange membrane fuel cell (PEMFC) stack developed in our previous work achieved peak volumetric power density and specific power of 2,715.9 $\mathrm{W} \mathrm{L}^{-1}$ and $2,157.9 \mathrm{~W} \mathrm{~kg}^{-1}$, respectively. However, there still existed perforated bipolar plates and the carbon fiber gas diffusion layer (GDL) was easy to cause damage during the fabrication process of undulate membrane electrode assembles (MEAs). In the present study, sintered stainless steel fiber felt (SSSFF) was employed to work as metallic GDL (MGDL) and bipolar plates simultaneously. Compound membrane electrode assembles (CMEAs) with serpentine and interdigitated flow channels were designed and fabricated using stamping process. A single cell with
\end{abstract}

CMEA was assembled in house and the output performance was evaluated systemically. The results indicated that the peak volumetric power density and specific power of wavelike PEMFC single with CMEA are $5,764.0 \mathrm{~W} \mathrm{~L}^{-1}$ and $4,693.5 \mathrm{~W} \mathrm{~kg}^{-1}$ respectively. This study achieved a significant performance improvement due to the concept of CMEA and may propose a possible means to meet the DOE's 2020 technical target that volumetric power density is $2,500 \mathrm{~W} \mathrm{~L}^{-1}$ and specific power is $2,000 \mathrm{~W} \mathrm{~kg}^{-1}$ for stack.

Keywords: Compound MEA, Metallic GDL, PEM Fuel Cell, Specific Power, Volumetric Power Density

\section{Introduction}

The proton exchange membrane fuel cell (PEMFC) technology has drawn considerable attention during past two decades and has potential for automotive applications due to high energy density and low impact on environments [1, 2]. Nevertheless, commercialization of fuel cell vehicles still depends on achieving higher volumetric power density and specific power in order to compete with traditionally used energy conversion devices [3]. Take the commercial $10.5 \mathrm{~kW}$ stack from BALLARD ${ }^{\circledR}$ for example [4], the volumetric power density is $1,323 \mathrm{~W} \mathrm{~L}^{-1}$ and specific power is $981 \mathrm{~W} \mathrm{~kg}^{-1}$. However, the 2020 technical target of US Department of Energy (DOE) for automotive fuel cell power systems operating on direct hydrogen is that volumetric power density and specific power are $2,500 \mathrm{~W} \mathrm{~L}^{-1}$ and $2,000 \mathrm{~W} \mathrm{~kg}^{-1}$ for stack, respectively [5]. Typically, the bipolar plates account for approximately $80 \%$ of the stack volume and as much as $70 \%$ of the stack weight [6]. Therefore, optimization the stack architecture and usage of novel functional material to replace bipolar plates are two efficient ways to improve the fuel cell power density simultaneously.

In our previous work [7], a novel wave-like architecture for PEMFC stack based on undulate membrane electrode assembles (MEAs) and perforated bipolar plates were presented. Different from conventional plate-and-frame architecture, the wave-like architecture increased active area and achieved higher volumetric power density due to undulate MEAs. Moreover, perforated sheet metal was used as bipolar plates so that it could improve specific power. Simple flow field was designed and perforated bipolar plates were fabricated by stamping process. Besides, the MEAs with the pro-

["] Corresponding author, xmlai@sjtu.edu.cn 
jected active area of $4 \mathrm{~cm}^{2}$ were hot pressed into undulate shape. Experimental results indicated that the architecture of wave-like PEMFC stack achieved peak volumetric power density and specific power of $2,715.94 \mathrm{~W} \mathrm{~L}^{-1}$ and $2,157.86 \mathrm{~W} \mathrm{~kg}^{-1}$, respectively. However, perforated bipolar plates still occupied weight and space, and the corrosion and contact performance still needed to be improved. In addition, the carbon fiber GDL was easy to cause damage during the process of undulate MEAs fabrication and in turn influenced the reactant transport and water removal [8].

Porous metal, enjoying similar microscopic morphology to carbon paper, good mechanical properties, and electrical conductivity, has shown great potential to make metallic GDL (MGDL). Yuan et al. [9] reviewed the fabrication, characterization, and application of the porous metal material for PEMFC applications, including metal foams, perforated metals, and porous metal sinters. The author concludes that the porous metal has been proved to be a promising material for PEMFC application although there are still many challenges. In the aspect of metal foams, Kumar and Reddy [10] carried out an experimental investigation to validate the feasibility of treating metal foams as the gas flow fields in a PEMFC. Results showed that the fuel cell with $\mathrm{Ni}-\mathrm{Cr}$ metal foam achieved highest performance due to the reduced permeability of metal foams. Murphy et al. [11] utilized two types of flat-sheet porous metals, i.e., the nickel foam and expanded titanium, as the flow field materials. The stack achieved a power density of $967 \mathrm{~W} \mathrm{~kg}^{-1}$ and $846 \mathrm{~W} \mathrm{~L}^{-1}$, and the authors claimed that PEM fuel cell stacks with power densities over $1,500 \mathrm{~W} \mathrm{~kg}^{-1}$ and 1,200 $\mathrm{W} \mathrm{L}^{-1}$ could be produced with further refinement. In terms of perforated metals, Zhang et al. [12] employed perforated copper foil as diffusion layer for PEMFC and tested the performance in an operational fuel cell. The experimental results showed that the MGDL provided improved water management and enhanced the performance by increasing in-plane transport. Fushinobu et al. [13] examined the feasibility of micromachined titanium thin film as GDL for PEMFC. Through-hole diameter, throughhole patterning, and the thin film thickness were investigated to show the parameter dependence as well as the possible high performance with design optimization. As to porous metal sinters, Hottinen et al. [14] concentrated on evaluating the applicability of titanium sinter that served as a gas diffusion backing (GDB) in the PEMFC. The performance curves showed that the titanium sinter produced poorer performance than the carbon paper, probably because of the higher contact resistance between the sinter and MEA. The authors also simply discussed the possibility of directly using such a metal-based sinter as gas diffusion paths in a free breathing fuel cell. Tang et al. [15, 16] and Zhou et al. [17] adopted porous copper fiber sintered felt as a novel porous flow field in PEMFCs and catalyst support of methanol steam reformer for hydrogen production. The characterization of porous copper fiber sintered felts was evaluated by experiments and the performance of PEMFC and methanol steam reforming microreactor was also studied. In our previous work [18], the feasi- bility of using sintered stainless steel fiber felt (SSSFF) as GDL in PEMFCs was evaluated. The SSSFF was deposited with an amorphous carbon (a-C) film by closed field unbalanced magnetron sputter ion plating (CFUBMSIP) to enhance the corrosion resistance and reduce the contact resistance. The characteristics of treated SSSFF, including microscopic morphology, mechanical properties, electrical conductivity, electrochemical behavior, and wettability characterization, were systematically investigated and summarized according to the requirements of GDL in PEMFC. Experimental results show that the SSSFF with a-C coating is a promising candidate used as gas diffusion layer in PEM fuel cells to improve fluid permeability of GDL under compression and PEMFC durability.

As the continuation of the previous work $[7,18]$, the present study adopts SSSFF to work as MGDL in wave-like PEMFC stack as shown in Figure 1(a). The MGDL allows direct and uniform access of the fuel and oxidant to the catalyst layer, collects the current and removes heat and water from the MEA. Moreover, the MGDL has good ductility so that complicated flow field can be fabricated by stamping process. Therefore, the conventional bipolar plates can be eliminated and the MGDL can represent a mechanical reinforcement for the floppy membrane and the very thin active layer. There is no conventional GDL-bipolar plate contact interface so that the cell performance can be expected to be improved due to the absence of voltage losses caused by contact resistance. An a-C film is deposited to enhance the electrochemical behavior and wettability characterization $[19,20]$.

a)
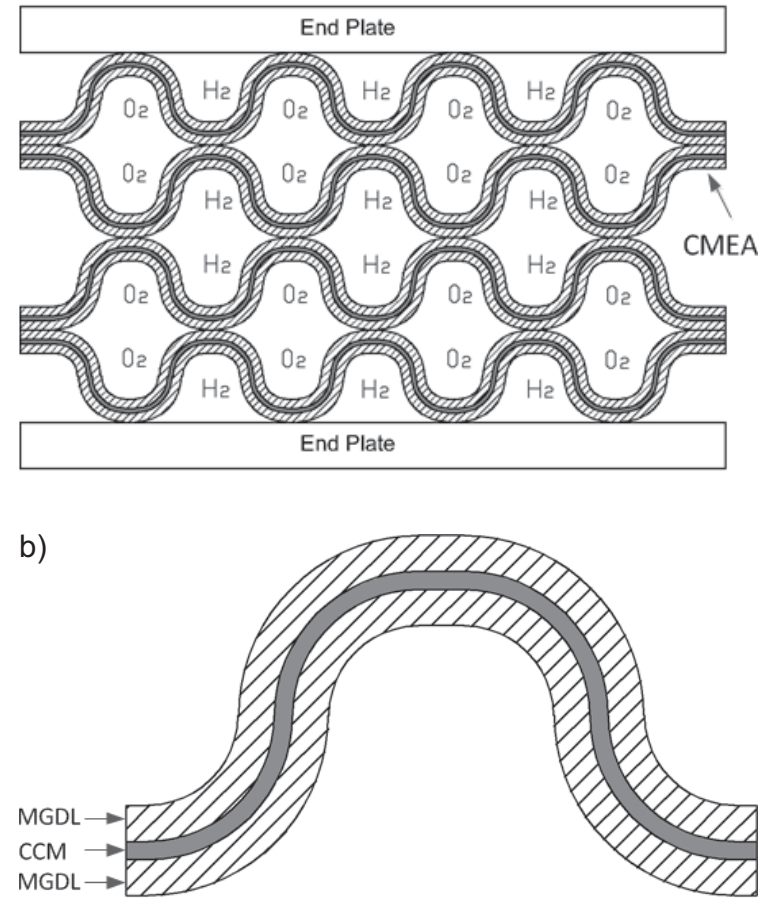

Fig. 1 The architecture of wave-like PEMFC stack. (a) Schematic diagram of the stack. (b) Schematic diagram of the CMEA. 
As shown in Figure 1(b), compound membrane electrode assembles (CMEAs) composed of two MGDLs and a catalyst-coated membrane (CCM) is fabricated using hotpressing process and flow channel is design and fabricated using stamping process. A wave-like single cell with CMEA is assembled in house and the output performance is evaluated systemically. Volumetric power density and specific power of wave-like PEMFC with CMEA are achieved and performance improvement is analyzed compared to previous work.

\section{Design and Experiments}

\subsection{Flow Field Design of CMEA}

Flow field of CMEA was designed based on stamping process which is low-cost and suitable for mass production. According to the characters of stamping process, the flow channels on both sides of CMEA are different: while interdigitated flow field is stamped on one side of CMEA, serpentine flow field is formed naturally on other side. As shown in Figure 2(a), the end of the inlet flow channel represented by solid arrows is closed and the outlet flow channel represented by dotted arrows is open. A pressure difference between the inlet flow channel and outlet channel is then formed. The reactant gas is forced to penetrate into catalyst layer and unreacted gas goes through to the adjacent exit passageways. The interdigitated flow field requires higher pressure and enhances reactant utilization. Hence, it is suitable for hydrogen flow channel. Figure 2(b) shows serpentine flow field in which the reactant gas flows through MGDL and catalyst layers by diffusion. The flow channels are connected in series and the pressure drop is large. This type of flow filed is beneficial to abstraction of water and is suitable for cathode flow channel where the product water is produced. Reactants inlet and outlet, seal gasket slots and location holes were designed as well. The CMEA is $90 \mathrm{~mm} \times 90 \mathrm{~mm}$ in size and the active electrode area is $42.25 \mathrm{~cm}^{2}(65 \mathrm{~mm} \times 65 \mathrm{~mm})$. Fifteen flow channels are used to distribute reactant gas uniformly on the anode and cathode. The designed land width, channel width, and channel depth of flow channels are 1.2, 2.4, and $0.5 \mathrm{~mm}$, respectively.

\subsection{Fabrication of CMEA}

SSSFF-15 has been demonstrated to have similar morphological features to traditional carbon paper including porosity, pore size, and fiber diameter, and better mechanical properties including compressive modulus, tensile modulus, and ductility [18]. Therefore, a-C coated SSSFF-15 by CFUBMSIP was adopted as MGDL and the parameters are listed in Table 1. Nafion ${ }^{\circledR} 112$ was employed as PEM to keep consistent with previous work. Flow chart of fabrication process for CMEA is shown in Figure 3. The MEAs with platinum loading of $0.5 \mathrm{mg} \mathrm{cm}^{-2}$ for the anode and cathode as well as an active electrode area of $42.25 \mathrm{~cm}^{2}(65 \mathrm{~mm} \times 65 \mathrm{~mm})$ were

Table 1 Material characterization of a-C coated SSSFF-15 as MGDL [18].

\begin{tabular}{ll} 
Thickness $(\mathrm{mm})$ & 0.20 \\
\hline Porosity $(\%)$ & 79.0 \\
Gas permeability $\left(\mathrm{mL} \mathrm{mm} \mathrm{cm} \mathrm{m}^{-1} \mathrm{mmAq}^{-1}\right)$ & $2,410.8$ \\
Young's modulus $(\mathrm{GPa})$ & 8.0 \\
Tensile strength $(\mathrm{MPa})$ & 153.6 \\
Elongation $(\%)$ & 14.1 \\
In-plane resistivity $(\mathrm{m} \Omega \mathrm{cm})$ & 0.5 \\
Through-plane resistivity $(\mathrm{m} \Omega \mathrm{cm})$ & 24.7 \\
Corrosion current density $(-0.1 \mathrm{~V}$ vs. SCE, bubbled with & 9.6 \\
hydrogen) $\left(\mu \mathrm{A} \mathrm{cm} \mathrm{cm}^{-2}\right)$ &
\end{tabular}

b)
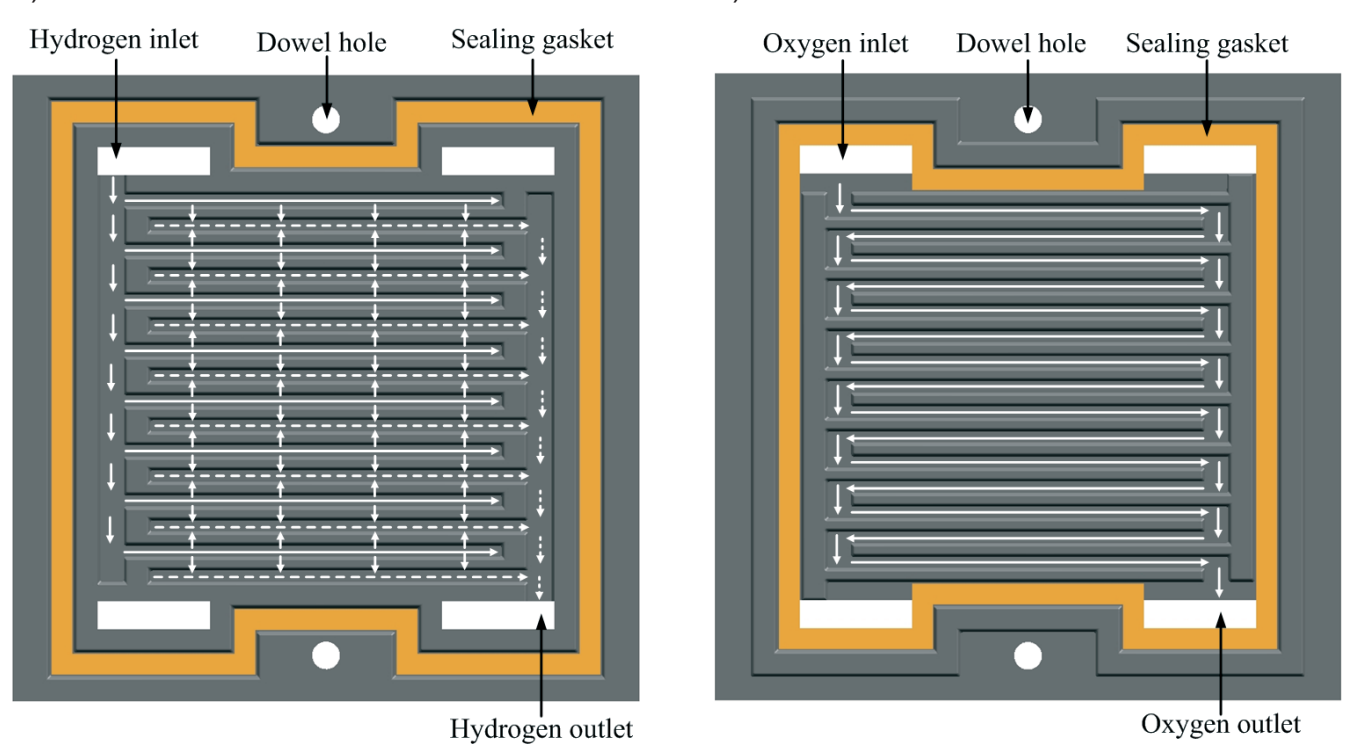

Fig. 2 Flow field design for stamped CMEA. (a) Anode side with interdigitated flow channels. (b) Cathode side with serpentine flow channels. 


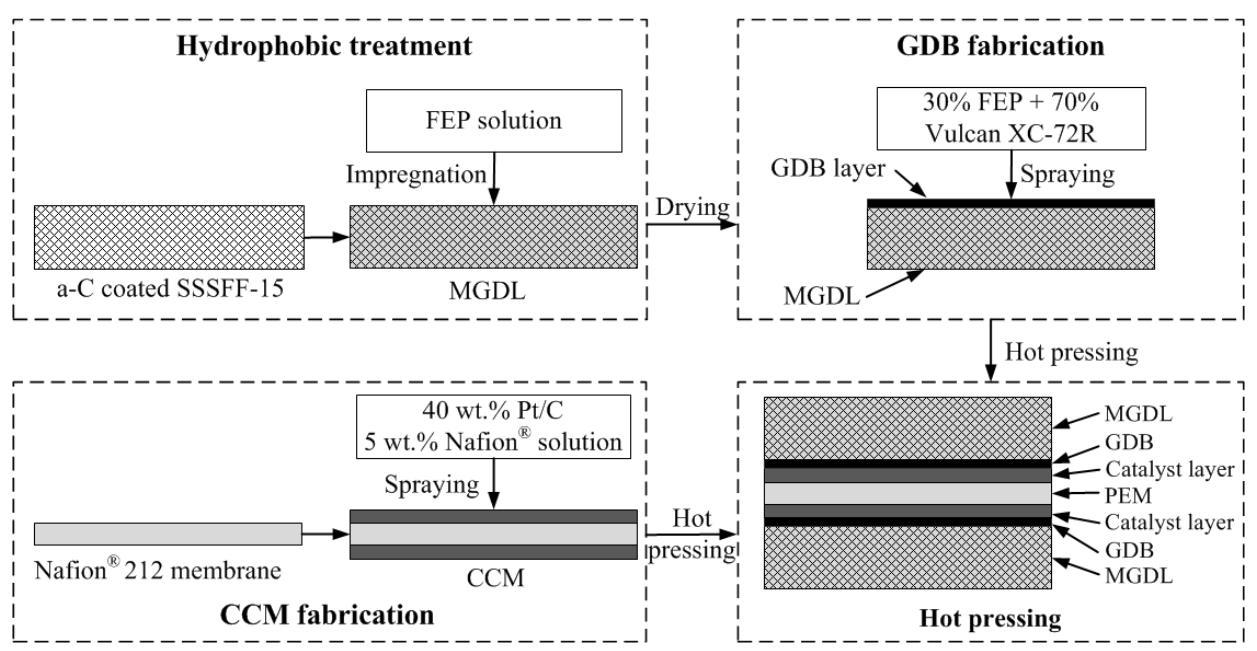

Fig. 3 Flow chart of fabrication process for CMEA.

fabricated with the help from WUT New Energy Co. Ltd. To enhance the hydrophobicity of MGDL, fluorinated ethylene propylene (FEP) solution was used for a-C coated SSSFF and the final FEP content is 10\% [21]. A mixed layer of FEP/C $(30 \% \mathrm{FEP}+70 \%$ Vulcan $\mathrm{XC}-72 \mathrm{R}$ from E-Tec, Inc., carbon loading of $1 \mathrm{mg} \mathrm{cm}^{-2}$ ) was bonded upon wet-proofed SSSFF GDL, which was used as anode and cathode GDB. A CCM was fabricated by spraying the catalyst ink containing 40 wt.\% Pt/C (E-Tec, Inc.), 5 wt.\% Nafion ${ }^{\circledR}$ solution (Du Pont, Inc.), and isopropyl alcohol on both sides of a pre-treated Nafion $^{\circledR} 212$ membrane. The prepared CCM was then dried at $70{ }^{\circ} \mathrm{C}$ prior to being assembled with wet-proofed SSSFF [22]. Finally, a 5-layer CMEA was fabricated by hot-pressing the pretreated a-C coated SSSFF GDL and CCM together at $120{ }^{\circ} \mathrm{C}$ under $8 \mathrm{MPa}$ for $90 \mathrm{~s}$ [23].

Forming mold system was designed and machined by milling process according to the flow field designed above. Zwick/Roell universal testing machine was used for forming process. The pressure head speed, forming force and real forming depth are $0.5 \mathrm{~mm} \mathrm{~min}^{-1}, 40 \mathrm{kN}$, and $0.508 \mathrm{~mm}$, respectively. Wave-like CMEA after stamping is shown in Figure 4.

a)

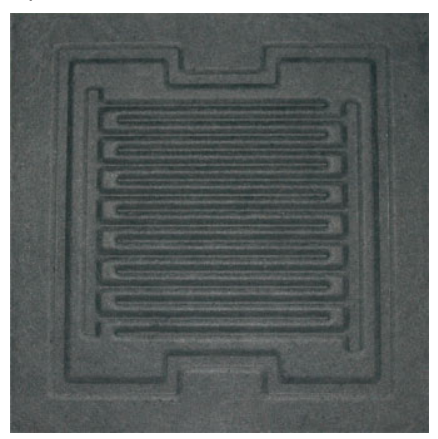

b)

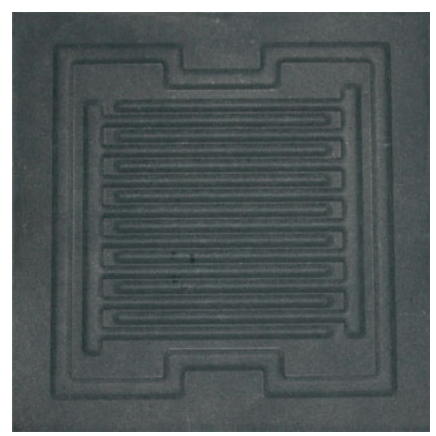

Fig. 4 Wave-like CMEA after stamping. (a) Anode side. (b) Cathode side.

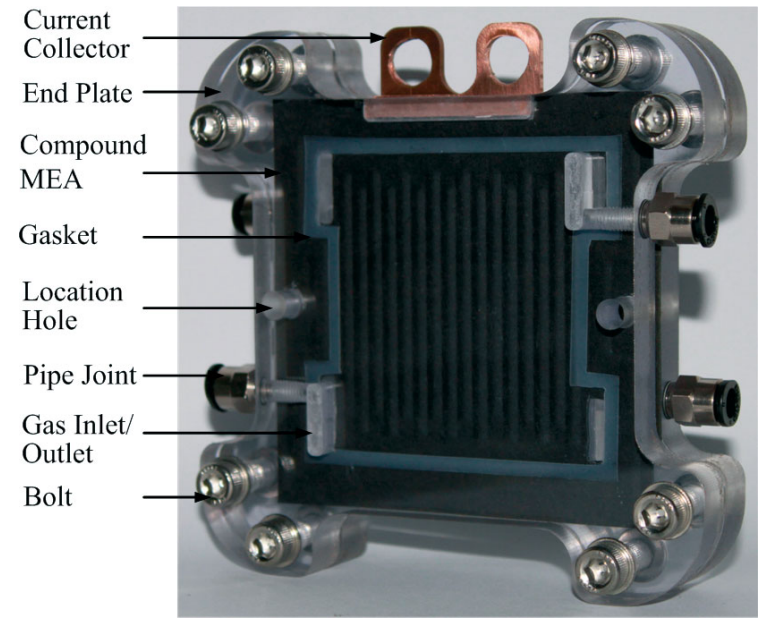

Fig. 5 Wave-like PEMFC single cell with CMEA.

\subsection{Single Cell Assembly and Tests}

As shown in Figure 5, a self-developed single cell was designed and fabricated in house using wave-like CMEA. $12.0 \mathrm{~mm}$ thick polycarbonate (PC) plates were applied as the end plates and $2.0 \mathrm{~mm}$ thick brass plates were used as the current collectors. Wave-like CMEAs, silicon seals and current collectors were clamped between two end plates by eight M4 screw joints and each had an assembly torque of about $4 \mathrm{~N} \mathrm{~m}$.

Performance of the single cell was evaluated by measuring $I-V$ curves using the NBT-100W fuel cell test system. The testing experiments were carried out under scanning current mode and the results were recorded after $1 \mathrm{~h}$ of stable operation. Stoichiometric ratio in anode and cathode was 1.2 and 2.0, respectively. Other parameters, including cell temperature, reactant humidification, and reactant pressure, were varied and investigated systematically in the following section. To investigate the lifetime performance, the single cell was operated at a cell voltage of $0.6 \mathrm{~V}$ and current density was recorded as a function of operating time. 


\section{Results and Discussion}

\subsection{Experimental Analysis of Operating Variables}

For the conventional PEMFC [24, 25], the behavior of the cell is mainly affected by the different operation parameters: cell temperature $\left(T_{\mathrm{c}}\right)$, relative humidification of the reactant streams $(\mathrm{RH})$, and pressure of the reactants $(P)$. Here, the influence of $T_{\mathrm{c}}, \mathrm{RH}$, and $P$ was also investigated to see whether there was any difference between wave-like PEMFC with CMEA and conventional PEMFC.

(i) The influence of cell temperature $T_{\mathrm{c}}$

To investigate the influence of cell temperature, the anode pressure $\left(P_{\mathrm{H}_{2}}\right)$ and cathode pressure $\left(P_{\mathrm{O}_{2}}\right)$ were set $0.3 \mathrm{MPa}$, and the reactants were fully humidified in both anode and cathode. Figure 6 shows the polarization curves at $T_{\mathrm{c}}=40,50,60,70$, and $80{ }^{\circ} \mathrm{C}$. Experimental results indicate that an increase of operation temperature leads to a better performance of the cell. This means that the positive effect of temperature on the ionic conductivity of the membrane prevails over the concurrent negative effect due to the reduction of the water content of the membrane with temperature [25]. However, the difference between 70 and $80^{\circ} \mathrm{C}$ is very small. The possible reason is that the performance increase is weakened by the increase of vapor partial pressure. Therefore, $T_{\mathrm{C}}=70^{\circ} \mathrm{C}$ is selected to be the operation temperature for wave-like PEMFC single cell.

(ii) The influence of reactant humidification $\mathrm{RH}$

The effect of the reactant humidification on the cell performance was investigated too. The runs were performed with $\mathrm{RH}_{\mathrm{H}_{2}}=\mathrm{RH}_{\mathrm{O}_{2}}=60,80$, and $100 \%$ while $T_{\mathrm{c}}=70{ }^{\circ} \mathrm{C}$ and $P_{\mathrm{H}_{2}}=P_{\mathrm{O}_{2}}=0.3 \mathrm{MPa}$. As shown in Figure 7 , the cell performance is improved by the increase of reactant humidification. This trend can be explained by the fact that the ionic conductivity of PEM is closely related to water content. The ionic conductivity can be improved and the Ohmic polarization can be reduced when the

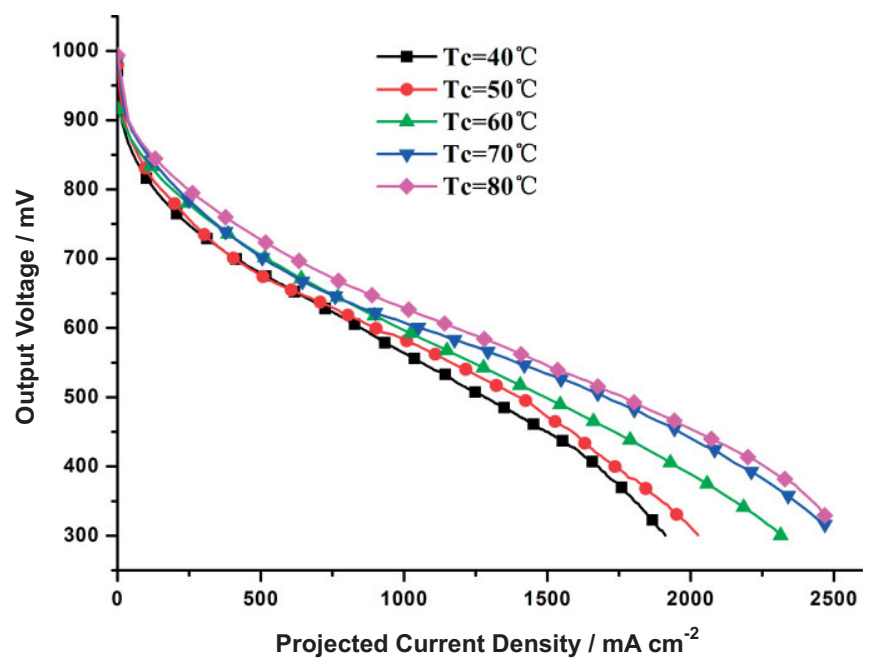

Fig. 6 The influence of cell temperature to wave-like PEMFC single cell performance.

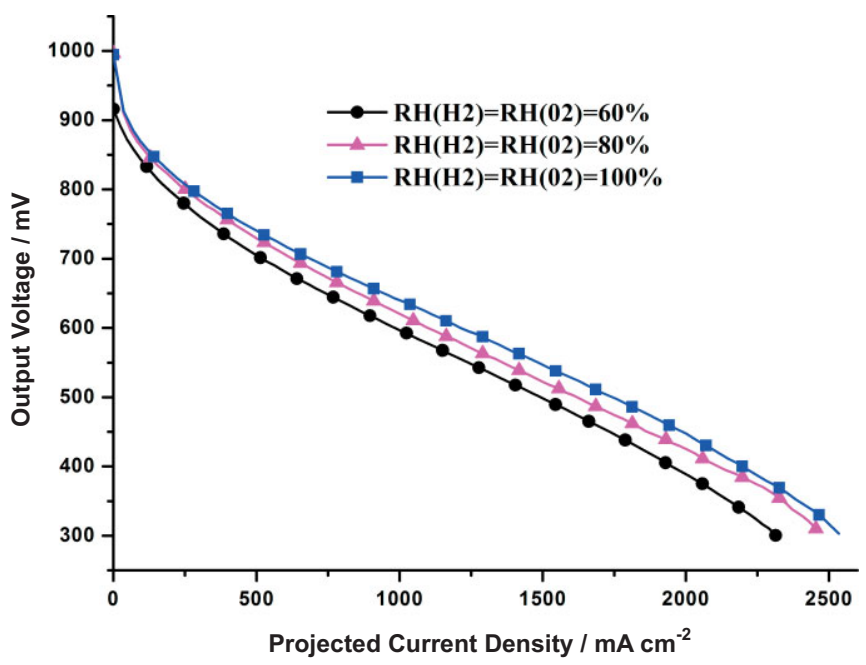

Fig. 7 The influence of relative humidification to wave-like PEMFC single cell performance.

PEM is at saturated state, thus the cell performance can be improved [25]. Therefore, $\mathrm{RH}_{\mathrm{H}_{2}}=\mathrm{RH}_{\mathrm{O}_{2}}=100 \%$ is preferred for wave-like PEMFC single cell.

(iii)The effect of reactant pressure $P$

A series of tests were also carried out to observe the effect of the reactant pressure. The operating temperature $T_{\mathrm{c}}$ was fixed at $70{ }^{\circ} \mathrm{C}$ and the relative humidification $\mathrm{RH}_{\mathrm{H}_{2}}=\mathrm{RH}_{\mathrm{O}_{2}}=100 \%$. The reactant pressures were varied from $0.1,0.2$, and $0.3 \mathrm{MPa}$, and the same pressure was imposed on both the anode and the cathode. The polarization curves are shown in Figure 8. The performance always improves when the operating pressure increases. This is mainly because the increase of reactant pressure can improve the hydrogen and oxygen diffusion capacity through the electrode layer. Thereby, the concentration loss can be reduced and cell performance can be improved [25]. However, the increase of reactant pressure must consume more pumping power. Therefore, reactant

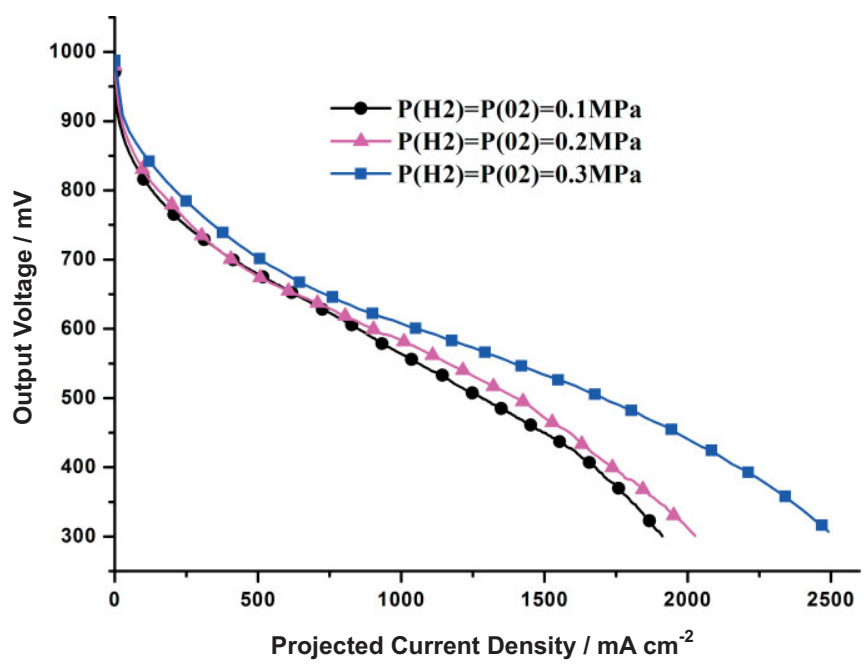

Fig. 8 The influence of reactants pressure to wave-like PEMFC single cell performance. 
pressure of $0.3 \mathrm{MPa}$ is selected considering the system efficiency.

To sum up, the influence of operation parameters including cell temperature, relative humidification, and reactant pressure to the performance of wave-like PEMFC with CMEA is similar to conventional plate-and-frame architecture PEMFC. Operating variables with $T_{\mathrm{c}}=70{ }^{\circ} \mathrm{C}, \mathrm{RH}_{\mathrm{H}_{2}}=\mathrm{RH}_{\mathrm{O}_{2}}=$ $100 \%$ and $P_{\mathrm{H}_{2}}=P_{\mathrm{O}_{2}}=0.3 \mathrm{MPa}$ are chosen for performance evaluation of wave-like PEMFC with CMEA.

\subsection{Single Cell Performance Analysis}

The performance of wave-like PEMFC single cell can be evaluated by using polarization curves including the current versus voltage $(I-V)$ and current versus power $(I-P)$ curves. Figure 9 illustrates the polarization curves of the wave-like single cell with CMEA. The open circuit voltage (OCV) of the single cell is $987.2 \mathrm{mV}$. The peak power density of the single cell is $1,049.8 \mathrm{~mW} \mathrm{~cm}^{-2}$ at a current density of $2,236.3 \mathrm{~mA} \mathrm{~cm}^{-2}$, while the power density is $908.4 \mathrm{~mW} \mathrm{~cm}^{-2}$ at $0.6 \mathrm{~V}$. The peak power density of the single cell using undulate MEAs and perforated bipolar plates in our previous work is $560.5 \mathrm{~mW} \mathrm{~cm}^{-2}$ and the power density at $0.6 \mathrm{~V}$ is $434.1 \mathrm{~mW} \mathrm{~cm}^{-2}$ [7]. It is obvious that the cell performance is greatly improved by the concept of CMEA.

According to electrochemical kinetics [24], the output cell voltage $V_{\mathrm{c}}$ in a real running fuel cell can be expressed as following:

$V_{\mathrm{c}}=E-V_{\mathrm{act}}-V_{\mathrm{Ohm}}-V_{\mathrm{conc}}$

where $E$ is reversible $\mathrm{OCV}, V_{\text {act }}, V_{\mathrm{Ohm}}$, and $V_{\text {conc }}$ are activation loss, Ohmic loss, and contrastration loss, respectively.

The activation loss arises from the need to move electrons and to break and form chemical bonds in the anode and cathode. It depends strongly on the operating temperature and the reactants partial pressure. Compared to the operating conditions, it can be concluded that the acitivation loss is not

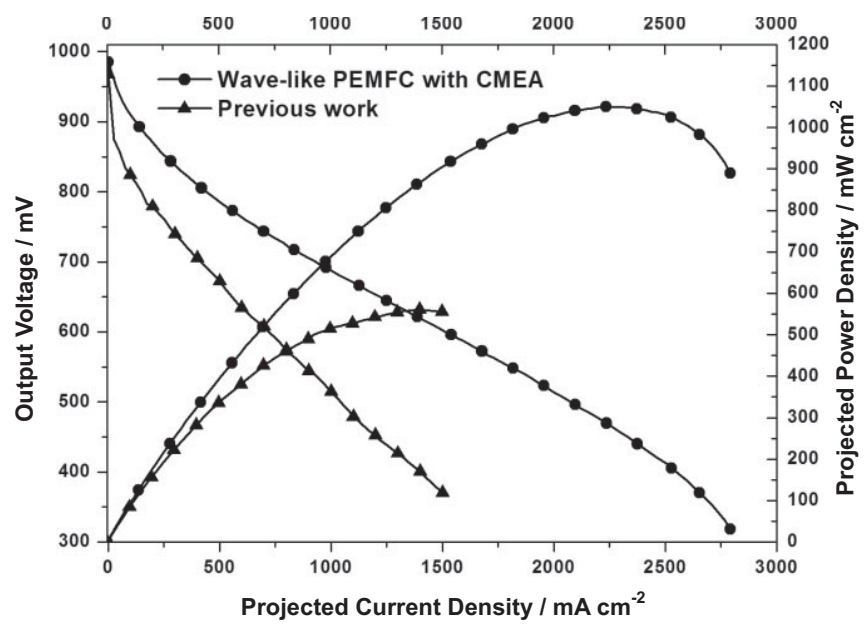

Fig. 9 The performance of wave-like PEMFC single cell with CMEA. the main factor to the performance variation. The performance improvement can be explained by the following three causes. Firstly, the SSSFF GDL has good ductility so that the catalyst layer can still be well supported after stamping process. While in the previous work, the wave-like MEA was hot press by the rigid mould with channels, the carbon fiber may be damaged and the catalyst layer can not be well protected. Secondly, SSSFF GDL can work as GDL and bipolar plate simultaneously, thus the interface of GDL and bipolar plate is dismissed and the interfacial contact resistance is reduced greatly. The Ohmic voltage $V_{\mathrm{Ohm}}$ is thus reduced correspondingly. That is the possible reason that the $I-V$ curve slope of wave-like PEMFC stack with undulate MEAs and perforated bipolar plates is larger than wave-like PEMFC stack with CMEA. Finally, the perforated bipolar plate has lots of via holes and the mass transfer performance is lower than SSSFF which has similar microscopic morphology as carbon paper. Therefore, the concentration voltage loss $V_{\text {conc }}$ of wave-like PEMFC stack with CMEA is lower than that with perforated bipolar plates.

Figure 10 presents the output current density degradation of the single cell during $100 \mathrm{~h}$ of continuous operation. The degradation curves can be fitted by the least squares linear regression [19]:

$i(t)=a-b t$

where $i$ stands for the current density $\left(\mathrm{mA} \mathrm{cm}^{-2}\right), t$ is the operating time (h), $a$ and $b$ are constant determined by linear regression.

Therefore, the performance degradation (PD) after $100 \mathrm{~h}$ of continuous operation can be defined as:

$\mathrm{PD}=\frac{i(0)-i(100)}{i(0)}=3.1 \%$

This degradation is mainly due to SSSFF GDL corrosion which decreases the ionic conductivity of the electrolyte

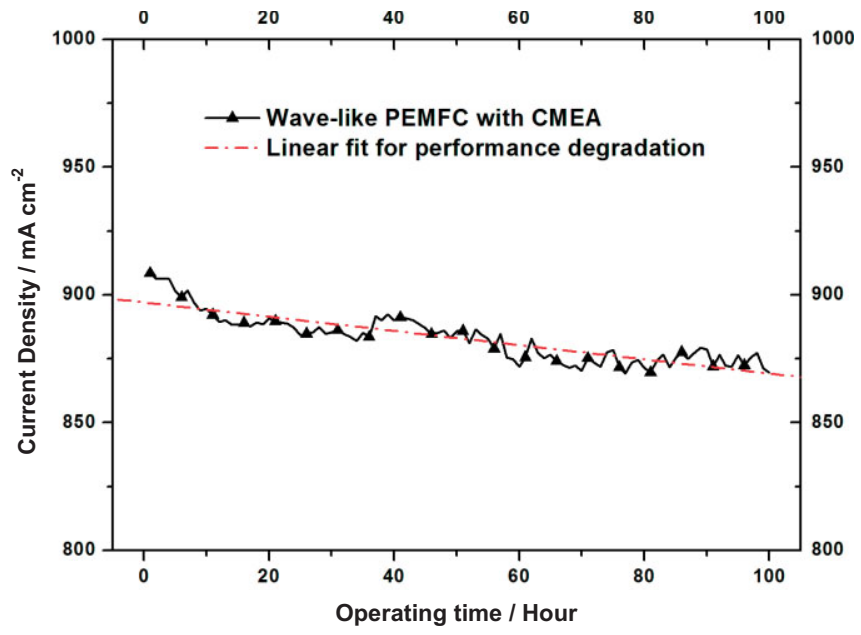

Fig. 10 Lifetime performance of wave-like PEMFC single cell at a cell voltage of $0.6 \mathrm{~V}$ during $100 \mathrm{~h}$ of continuous operation. 


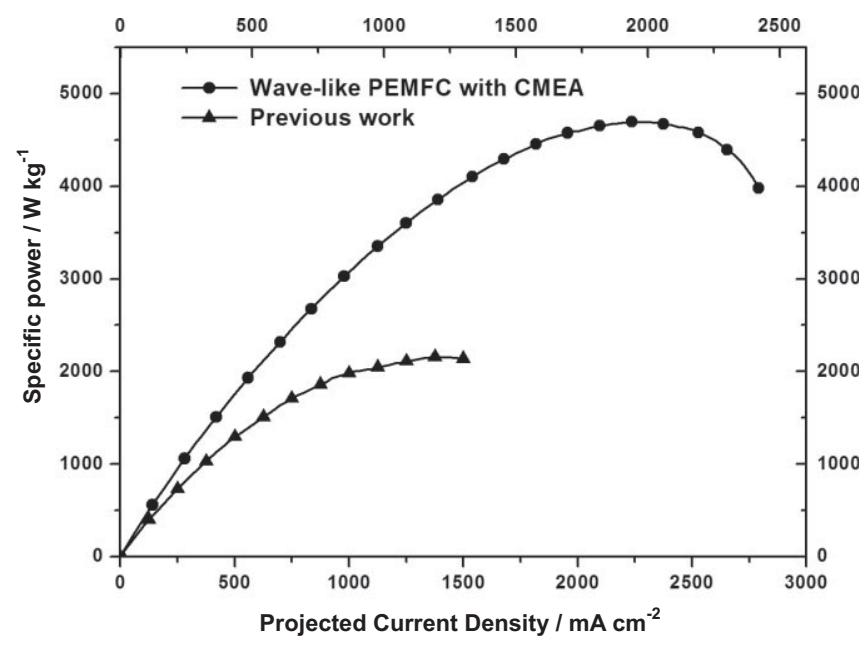

Fig. 11 Volumetric power density of wave-like PEMFC single cell with CMEA.

membrane and increases the charge transfer resistance. However, it is worthy that MEA itself also exits degradation including membrane and catalyst layer decay [18]. Anyway, great efforts should still be made to improve anticorrosion performance of MGDL by optimizing CFUBMSIP process in future.

\subsection{Volumetric Power Density and Specific Power Analysis}

High volumetric power density and specific power are required for PEMFCs to compete with traditionally used energy conversion devices. Volumetric power density and specific power of the single cell with CMEA are calculated using a CMEA-seal unit which is $9.45 \mathrm{~g}$ in weight and $0.95 \mathrm{~mm}$ in thickness after assembly. As presented in Figure 11 and Figure 12, the peak volumetric power density and specific power are 5,764.0 $\mathrm{W} \mathrm{L}^{-1}$ and $4,693.5 \mathrm{~W} \mathrm{~kg}^{-1}$, respectively. Besides, the volumetric power density and specific power at $0.6 \mathrm{~V}$ are $4,987.6 \mathrm{~W} \mathrm{~L}^{-1}$ and $4,061.4 \mathrm{~W} \mathrm{~kg}^{-1}$. The peak volumetric power density and specific power of single

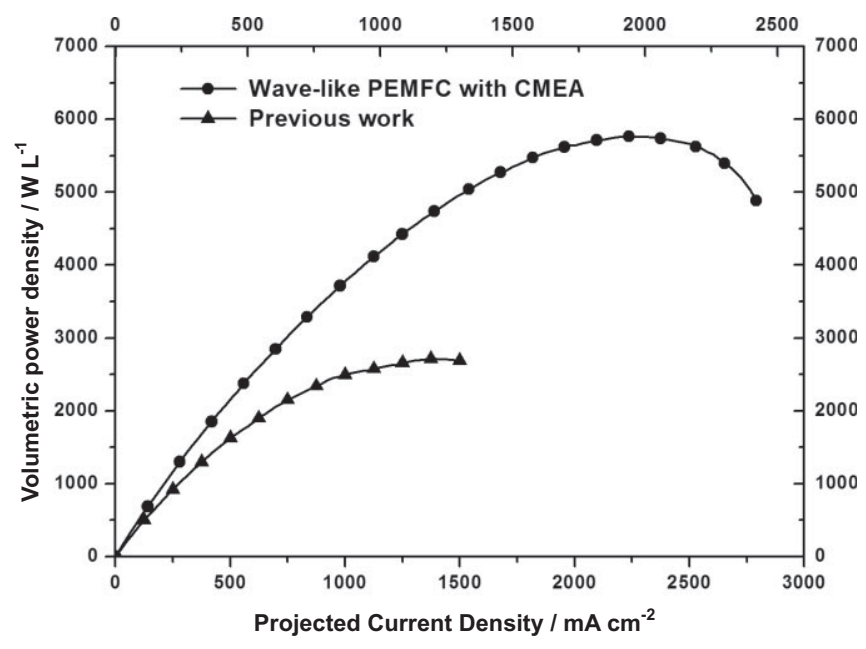

Fig. 12 Specific power of wave-like PEMFC single cell with CMEA. cell with CMEA are 2.12 and 2.17 times than that with undulate MEA and perforated bipolar plates in our previous work [7]. It should be pointed out that the volumetric power density and specific power would be lower when considering the contributions of the end plates and bolts. However, this effect can be compensated by increasing the number of cells and enlarging the flow field area. As a result, wave-like PEMFC with CMEA fabricated by stamping process might be a feasible approach to meet the DOE target that the stack volumetric power density is $2,500 \mathrm{~W} \mathrm{~L}^{-1}$ and the stack specific power is $2,000 \mathrm{~W} \mathrm{~kg}^{-1}$ for automotive fuel cell power systems operating on direct hydrogen [5].

\section{Conclusion}

As the continuation of the previous work, this study employed SSSFF to work as MGDL in wave-like PEMFC stack. The SSSFF-15 with similar microscopic morphology, good mechanical properties, and electrical conductivity was adopted to take into account the role of conventional GDL and bipolar plates simultaneously. An a-C film was deposited to enhance the electrochemical behavior and wettability characterization. CMEAs with serpentine and interdigitated flow channels were design and fabricated using stamping process. A single cell with CMEA was assembled in house and the influence of operating variables was investigated systemically. The peak power density of the single cell was $1,049.8 \mathrm{~mW} \mathrm{~cm}{ }^{-2}$ at a current density of $2,236.3 \mathrm{~mA} \mathrm{~cm}$, while the power density was $908.4 \mathrm{~mW} \mathrm{~cm}^{-2}$ at $0.6 \mathrm{~V}$. The peak power density of the single cell in our previous work was $560.5 \mathrm{~mW} \mathrm{~cm}^{-2}$ and the power density at $0.6 \mathrm{~V}$ was $434.1 \mathrm{~mW} \mathrm{~cm}^{-2}$. Besides, the results indicated that the peak volumetric power density and specific power of wave-like PEMFC single cell with CMEA are $5,764.0 \mathrm{~W} \mathrm{~L}^{-1}$ and $4,693.5 \mathrm{~W} \mathrm{~kg}^{-1}$, respectively, which are 2.12 and 2.17 times higher than that with undulate MEA and perforated bipolar plates in our previous work. This study achieved a significant performance improvement due to the concept of CMEA and may propose a possible means to meet the DOE's 2020 technical target that volumetric power density is $2,500 \mathrm{~W} \mathrm{~L}^{-1}$ and specific power is $2,000 \mathrm{~W} \mathrm{~kg}^{-1}$ for stack. However, challenges in anticorrosion of MGDL, electrode connection and cooling channel remain the focus of ongoing efforts and future work.

\section{Acknowledgements}

This work was carried out within the projects supported by National Natural Science Foundation of China (Grant No. 51121063 and Grant No. 50930005) and Major International (Regional) Joint Research Project of NSFC (Grant No. 50820125506). The study was also supported by the Program of Introducing Talents of Discipline to Universities (Grant No. B06012), SAIC (Shanghai Automotive Industry Corporation) through the project "Manufacturing technology of metallic PEM fuel cell bipolar plates for vehicle applications", 
and Scholarship Award for Excellent Doctoral Student granted by the Ministry of Education of China. The authors would like to acknowledge their financial support.

\section{References}

[1] D. Mei, M. Qian, B. Liu, B. Jin, Z. Yao, Z. Chen, J. Power Sources 2012, 205, 367.

[2] B. K. Kakati, V. Mohan, Fuel Cells 2008, 8, 45.

[3] S. Gamburzev, A. J. Appleby, J. Power Sources 2002, $107,5$.

[4] http://www.ballard.com/files/PDF/Material_Handling/9SSL.pdf.

[5] U.S. Department of Energy, Technical Plan-Fuel cells, 2011, pp. 3.4-18, http:/ / www1.eere.energy.gov / hydrogenandfuelcells/mypp/pdfs/fuel_cells.pdf.

[6] C. Du, P. W. Ming, M. Hou, J. Fu, Q. Shen, D. Liang, Y. Fu, X. Luo, Z. Shao, B. Yi, J. Power Sources 2010, 195, 794.

[7] P. Y. Yi, L. F. Peng, X. M. Lai, D. A. Liu, J. Ni, Fuel Cells 2010, 10, 111.

[8] P. Y. Yi, L. F. Peng, X. M. Lai, J. Ni, ASME J. Fuel Cell Sci. Technol. 2011, 8, 011011.

[9] W. Yuan, Y. Tang, X. Yang, Z. Wan, Appl. Energy 2012, 94, 309.

[10] A. Kumar, R. G. Reddy, J. Power Sources 2004, 129, 62.

[11] O. J. Murphy, A. Cisar, E. Clarke, Electrochim. Acta 1998, $43,3829$.

[12] F. Y. Zhang, S. G. Advani, A. K. Prasad, J. Power Sources 2008, 176, 293.
[13] K. Fushinobu, D. Takahashi, K. Okazaki, J. Power Sources 2006, 158, 1240.

[14] T. Hottinen, M. Mikkola, T. Mennola, P. Lund, J. Power Sources 2003, 118, 183.

[15] Y. Tang, W. Yuan, M. Pan, Z. Wan, Int. J. Hydrogen Energy 2010, 35, 9661.

[16] Y. Tang, W. Zhou, M. Q. Pan, H. Q. Chen, W. Y. Liu, H. Yu, Int. J. Hydrogen Energy 2008, 33, 2950.

[17] W. Zhou, Y. Tang, M. Q. Pan, X. L. Wei, H. Q. Chen, J. H. Xiang, Int. J. Hydrogen Energy 2009, 34, 9745.

[18] P. Y. Yi, L. F. Peng, X. M. Lai, M. T. Li, J. Ni, Int. J. Hydrogen Energy 2012, 37, 11334.

[19] P. Y. Yi, L. F. Peng, L. Z. Feng, P. Gan, X. M. Lai, J. Power Sources 2010, 195, 7061.

[20] K. Feng, Y. Shen, H. Sun, D. Liu, Q. An, X. Cai, P. K. Chu, Int. J. Hydrogen Energy 2009, 34, 6771.

[21] W.-M. Yan, C.-Y. Hsueh, C.-Y. Soong, F. Chen, C.-H. Cheng, S.-C. Mei, Int. J. Hydrogen Energy 2007, 32, 4452.

[22] M. Prasanna, E. A. Cho, T. H. Lim, I. H. Oh, Electrochim. Acta 2008, 53, 5434.

[23] H. Tang, S. Wang, S. P. Jiang, M. Pan, J. Power Sources 2007, 170, 140.

[24] M. G. Santarelli, M. F. Torchio, Energy Convers. Manage. 2007, 48, 40.

[25] J. T. Pukrushpan, A. G. Stefanopoulou, H. Peng, Control of Fuel Cell Power Systems-Principles, Modeling, Analysis and Feedbackdesign, Springer, New York 2004. 